\title{
Sport-related anxiety: current insights
}

Jessica L Ford

Kenneth Ildefonso

Megan L Jones

Monna Arvinen-Barrow

Department of Kinesiology, Integrative Health Care \& Performance Unit, University of Wisconsin-Milwaukee, Milwaukee, WI, USA

\section{Video abstract}

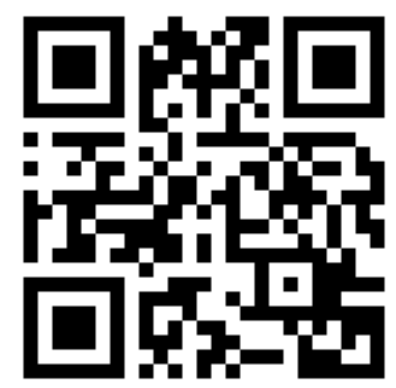

Point your SmartPhone at the code above. If you have a QR code reader the video abstract will appear. Or use: http://youtu.bel-4jFffwRI5sU
Correspondence: Monna Arvinen-Barrow Department of Kinesiology, Integrative Health Care and Performance Unit, Pavilion - Physical Therapy and Athletic Training, Room 370, 3409 North Downer Avenue, Milwaukee, WI 532II, USA

Tel + I 4I4 2293360

Email arvinenb@uwm.edu
This article was published in the following Dove Press journal:

Open Access Journal of Sports Medicine

27 October 2017

Number of times this article has been viewed

Abstract: To date, much research has been devoted to understanding how anxiety can affect sport performance, both in practice and in competitive settings. It is well known that sport has the potential for high levels of stress and anxiety, and that practicing and employing a range of psychological strategies can be beneficial in anxiety management. Equally, growing evidence also suggests that anxiety can play a role in sport injury prevention, occurrence, rehabilitation, and the return to sport process. The purpose of this paper is to provide current insights into sport-related anxiety. More specifically, it will provide the reader with definitions and theoretical conceptualizations of sport-related anxiety. This will be followed by making a case for considering the term "performance" to be broader than activities associated with sport-related performance in practice and competition, by including performance activities associated with sport injury prevention, rehabilitation, and the return to sport process. The paper will then highlight the importance of recognizing early signs and symptoms of anxiety, and the potential need for referral. Finally, the conclusions will emphasize the need for appropriate, client-specific, and practitioner competent care for athletes experiencing sport-related anxiety.

Keywords: anxiety, sport, performance, injury, sport medicine professional, sport psychology, mental health

\section{Introduction}

\section{I don't think you're human if you don't get nervous. Sidney Crosby.}

Sidney Crosby, a two-time Olympic gold medalist, a World and a Junior World champion, a two-time National Hockey League Most Valuable Player, a three-time Stanley Cup Champion, and a six-time National Hockey League all-star, is certainly not the only athlete who reports experiencing nerves when performing in his sport. Nor is he the only athlete who has developed routines to combat such nerves. This is unsurprising, as sport psychology researchers have somewhat unanimously agreed that competitive sport has the potential for high levels of stress and anxiety. ${ }^{1}$ Equally, practicing and employing a range of psychological strategies to combat potential negative emotional states such as sport-related anxiety has become an integral part of a competitive athlete's performance preparation. ${ }^{1,2}$ The purpose of this article is to present the reader with current insights into sport-related anxiety. First, the article will define and theoretically conceptualize sport-related anxiety. Second, the article will introduce the reader to a broader concept of sport performance. In particular, the article will make a case for considering the term "performance" to be broader than activities associated with sport-related performance in practice and competition, by including performance activities associated with sport injury prevention, rehabilitation, and the return to sport process. Considering the primary audience of the article, 
the focus will then shift to the role of anxiety during different phases of sport injury: occurrence, rehabilitation, and return to sport. This will be followed by a short conclusion of the key points of the article, emphasizing the role of sport medicine professionals in providing appropriate, client-specific, and practitioner competent care for athletes experiencing sport-related anxiety.

\section{Defining anxiety}

Typically defined as "an unpleasant psychological state in reaction to perceived stress concerning the performance of a task under pressure", ${ }^{3}$ anxiety is a common emotional state experienced by athletes at all levels of performance. In general, anxiety is made up of cognitive (e.g., worrying thoughts and apprehensions) and somatic (e.g., degree of physical activation) components. Anxiety can manifest itself as a stable part of one's personality known as trait anxiety, or as a temporary, more malleable, situation-specific state anxiety. ${ }^{2}$ In a sport context, anxiety is often regarded as a typical response to a situation where an athlete's skills are being evaluated. ${ }^{4}$ Anxiety is often characterized by a range of physiological (e.g., sweating, increased heart rate), behavioral (e.g., biting fingernails, fidgeting), and/or cognitive (e.g., negative thoughts, inattention) signs and symptoms (for more details on anxiety, please see Weinberg and Gould ${ }^{2}$ ). A recent review revealed that the terms competitive state anxiety, competitive trait anxiety, somatic anxiety, cognitive anxiety, behavioral anxiety, performance anxiety, facilitative anxiety, debilitative anxiety, competition anxiety, and pre- and postcompetition anxiety have also been used to describe sport-related anxiety. For more details, please see recent review by Patel et al. ${ }^{5}$ Based on the definitions above, the current paper will adopt a definition of sport-related anxiety as being a trait and/or state-like response to a stressful sport-related situation, which the individual perceives as potentially stressful, resulting in a range of cognitive appraisals, behavioral responses, and/ or physiological arousals.

\section{Theoretical conceptualizations}

How anxiety impacts performance has received much attention in the sport psychology literature. Some of the early theories include the inverted-U hypothesis, ${ }^{6}$ drive theory, ${ }^{7}$ and reversal theory. ${ }^{8}$ The inverted-U hypothesis suggests that performance and anxiety should be viewed on an inverted U-shaped continuum. According to Yerkes and Dodson, ${ }^{6}$ low arousal/anxiety leads to decreases in performance, and increases in arousal/anxiety can facilitate performance up to an optimal level. The model also assumes that beyond this point, additional arousal/anxiety causes performance to decline. In contrast, the drive theory proposes the relationship between performance and state anxiety as linear, with higher anxiety leading to better performance. ${ }^{7}$ The model proposes that high levels of arousal/state anxiety will increase an individual's dominant responses to the task, and thus resulting in stronger quality performances. Finally, the reversal theory ${ }^{8}$ puts forth an additional dimension to the anxiety-performance relationship by suggesting that the ways in which arousal/anxiety affects performance depend on the individual's own interpretation of their arousal/anxiety levels as either debilitative or facilitative.

These early theories have provided a useful foundation for more multidimensional models to emerge. One of the first comprehensive multidimensional models that emerged is the conceptual model of athletic performance anxiety by Smith and Smoll. ${ }^{4}$ The Smith and Smoll conceptual model proposed that when faced with a competitive sporting situation, an individual will make cognitive appraisals of the perceived imbalance of the situational demands, resources, consequences, and the "meaning" of consequences. These cognitive appraisals have a reciprocal relationship with physiological arousal, and the aforementioned stress response process is also influenced by the individual's cognitive and somatic sport-specific trait anxiety and existing defensive operations such as range of coping strategies. ${ }^{4}$ Depending on the stress response, task-relevant or task-irrelevant cognitive, behavioral, and physiological responses will ensue, which will influence subsequent sport performance. ${ }^{4}$ The model also proposes that the sport performance itself will also influence any subsequent competitive sport situations, and any subsequent cognitive appraisals and physiological arousals of such situations (for more details of the model, please see Smith and $\mathrm{Smoll}^{4}$ ).

Since the development of the Smith and Smoll model, ${ }^{4}$ many other theoretical models (Table 1) have also been developed with the aim to explain sport-related anxiety and its relationship with performance. These include the multidimensional anxiety theory, ${ }^{9}$ catastrophe theory, ${ }^{10}$ and the Individual Zones of Optimal Functioning. ${ }^{11}$ The multidimensional anxiety theory ${ }^{9}$ draws from the earlier models by proposing that cognitive state anxiety is negatively related to performance, whereas somatic state anxiety is related to performance in an inverted-U manner. Similarly, the catastrophe theory ${ }^{10}$ builds on earlier work by supporting the inverted-U hypothesis, but only when the individual has low cognitive state anxiety. Finally, the Individual Zones of Optimal Functioning model ${ }^{11}$ suggests that for an optimal 
Table I Brief descriptions of various models developed to explain sport-related anxiety and its relationship with performance

\begin{tabular}{|c|c|}
\hline $\begin{array}{l}\text { Inverted-U Hypothesis (Yerkes and } \\
\text { Dodson }{ }^{6} \text { ) }\end{array}$ & $\begin{array}{l}\text { This view holds that low arousal/anxiety leads to decreases in performance, and increases in arousal/ } \\
\text { anxiety can facilitate performance up to an optimal level, however, beyond this point additional } \\
\text { arousal/anxiety causes performance to decline. }\end{array}$ \\
\hline rive Theory (Hull') & $\begin{array}{l}\text { This view holds that relationship between situation specific state anxiety and performance is linear; } \\
\text { higher anxiety leads to better performance. }\end{array}$ \\
\hline Reversal Theory $\left(\right.$ Apter $\left.^{8}\right)$ & $\begin{array}{l}\text { This view holds that the ways in which arousal/anxiety affects performance depend on the individual's } \\
\text { own interpretation of their arousal/anxiety levels. }\end{array}$ \\
\hline $\begin{array}{l}\text { The Conceptual Model of Athletic } \\
\text { Performance Anxiety (Smith and Smoll }{ }^{4} \text { ) }\end{array}$ & $\begin{array}{l}\text { This view holds that arousal/anxiety can influence individuals' stress response to a competitive } \\
\text { situation, which in turn will influence performance through a range of physiological, behavioral, and/or } \\
\text { cognitive responses. }\end{array}$ \\
\hline $\begin{array}{l}\text { Multi-dimensional Anxiety Theory } \\
\text { (Martens et } \mathrm{al}^{9} \text { ) }\end{array}$ & $\begin{array}{l}\text { This view holds that cognitive state anxiety is negatively related to performance, whereas somatic } \\
\text { state anxiety is related to performance in an inverted-U manner. }\end{array}$ \\
\hline Catastrophe Theory (Hardy and Parfitt ${ }^{10}$ ) & $\begin{array}{l}\text { This view holds that somatic anxiety is related to performance in an inverted-U fashion, but only } \\
\text { when the individual has low cognitive state anxiety. }\end{array}$ \\
\hline $\begin{array}{l}\text { Individual Zones of Optimal Functioning } \\
\text { Theory (Hanin") }\end{array}$ & $\begin{array}{l}\text { Holds the view that elite-level performers have an optimal zone of arousal/anxiety where they are } \\
\text { able to reach peak performances. If their arousal/anxiety is outside the zone (too low or too high), } \\
\text { performance will decline. }\end{array}$ \\
\hline
\end{tabular}

performance to occur, each individual has an optimal zone of arousal/anxiety where they are able to reach peak perfor mances. If their arousal/anxiety is outside of the zone (too low or too high), performance will decline.

These theoretical relationships associated with sportrelated performance anxiety have been among the most debated domains within sport psychology, ${ }^{12}$ and empirical results appear to be inconsistent. ${ }^{3}$ However, when examining the theoretical conceptualizations and empirical evidence $e^{5,13-15}$ as a collective whole, few key tenets remain constant and are generally agreed upon: 1) sport-related anxiety has an effect on performance; 2) depending on the individual and the situation, such effect on performance can be either negative or positive; 3 ) and the direction of such effect on performance is typically a result of individual's cognitive, behavioral, and physiological responses to the potentially stressful sporting situation.

\section{Sport performance: broadening the concept}

It is important to note that sport-related anxiety is considered to be an unpleasant response generally associated with the stress of participating in sport. Traditionally, sport performance as a concept has included participation in activities that relate to regular practice and competition of ones' sport; however, more recently, this has also included performance in activities that relate to sport injury prevention, rehabilitation, and the return to sport process. ${ }^{16}$ At first glance, these two domains may appear separate, however; it is one of the fundamental tenets of this paper that they should be viewed as interconnected. Thus far, research has highlighted that some of the antecedents of anxiety in practice and/or competition include increased intensity of the activity performed, ${ }^{17,18}$ athlete's personality, ${ }^{19,20}$ history and intensity of stressors, ${ }^{21}$ and their existing coping strategies, ${ }^{22}$ to name a few.

Coincidentally, the same stressors that have been found to facilitate the development of anxiety in practice or competitive settings are also likely to be contributors to sport injury occurrence. ${ }^{23}$ Thus far, research has highlighted that an individual's poor stress response to a stressful practice or competitive situation can influence their increased risk of sport injury, ${ }^{24-26}$ and that anxiety is one of the key personality factors that affect sport injury onset. ${ }^{27-29}$ In a similar way, the same stressors will continue to influence subsequent injury rehabilitation and, if not addressed appropriately, can also impact physical and psychosocial rehabilitation outcomes, ${ }^{30}$ as well as subsequent return to sport participation. ${ }^{31}$ Given the ample research that has focused on the impact of anxiety on competitive sport performance, ${ }^{5,13-15}$ and with the attempt to provide the reader with current insights into sport-related anxiety, the following sections will focus on the role of anxiety in one specific sport performance domain: sport injury occurrence, rehabilitation, and return to sport.

\section{Anxiety and sport injury occurrence}

Similar to the Smith and Smoll model ${ }^{4}$, theoretical conceptualizations developed to explain sport injury occurrence have also centered around the cognitive appraisal physiological arousal stress response mechanism. ${ }^{23,32}$ In short, Andersen and Williams' model ${ }^{23,32}$ of stress and athletic injury proposes that when placed in a stressful athletic situation, the athlete will make cognitive appraisals of the following: the demands of the situation, their resources available, and the consequences of the potential outcomes of the situation. Known 
as the stress response, such appraisals are said to interact bidirectionally with physiological/attentional aspects, resulting in increased muscle tension, narrowing of visual field, and increased distractibility. Based on the stress response, a person can increase or decrease their potential risk of encountering sport injury. This stress response is directly or indirectly mediated by bidirectional interaction between an individual's personality, history of stressors, and available coping resources. Moreover, the stress response can also be alleviated by implementing a range of psychosocial stress management-based interventions. ${ }^{33}$ For more details on the model, please see Andersen and Williams' original work, ${ }^{23,32}$ or a recent review of the literature pertaining to the model by Appaneal and Habif. ${ }^{33}$

The stress and athletic injury model ${ }^{23,32}$ proposes that anxiety, as a personality variable, can act as an antecedent influencing the stress response-injury relationship. ${ }^{32}$ Support for the aforementioned has been found in the literature. ${ }^{24-29}$ Of all the personality variables studied to date, existing research has identified competitive trait anxiety as the most researched $^{33}$ and consistent variable associated with sport injury occurrence. ${ }^{16,34}$ For example, in a recent critically appraised topic review of trait anxiety as a risk factor for musculoskeletal injury in athletes, ${ }^{35} 66 \%$ of studies supported the competitive trait anxiety/musculoskeletal sport injury occurrence relationship. The study revealed that when competitive trait anxiety is considered in conjunction with other psychosocial variables such as cognitive worry, mood states like irritability, life stressors, and the presence of coping skills, it has the ability to predict athletic injury occurrence. ${ }^{35}$ However, in isolation, its ability to predict injury occurrence is small, ${ }^{35}$ providing further support to the multidimensional nature of the stress and athletic injury model. ${ }^{23,32}$

It is also likely that feelings of competitive trait anxiety that increase the risk of sport injury occurrence do not occur in isolation, but are rather intertwined with other cognitive appraisals related to the situation. For example, it is possible that the competitive trait anxiety-sport injury relationship is influenced by an athlete's perception of situational injury risk $^{36}$ and/or his/her perceived susceptibility to sport injury (PSSI). ${ }^{37}$ Some limited evidence in support of the aforementioned exists. Prospective research on 434 adult hockey, soccer, and football players found a positive relationship between athletes' perceptions of injury risk (i.e., fear of being injured) and probability of injury occurrence. ${ }^{38}$ The results from Reuter and Short ${ }^{38}$ further demonstrated that athlete's level of worry and concern was also positively associated with injury occurrence. In addition, those athletes with history of previous injuries were least confident in their ability to avoid reinjury and subsequently also experienced higher probabilities of reinjury overall. ${ }^{38}$

An individual's PSSI has also been found to be associated with neuroticism, ${ }^{39-41}$ a pertinent personality trait often related to trait anxiety. ${ }^{42}$ Since researchers have yet to explore the role of anxiety in sport injury occurrence in great detail, it might be advisable to extend the research to include these constructs as well. It is likely that the range of cognitive appraisals related to injury risk and susceptibility such as PSSI, perceived situational injury risk, and fear of reinjury should be examined in combination with neuroticism and potentially other personality constructs should be considered as potential antecedents to trait and state anxiety in a sport injury occurrence context. Moreover, very recently, Brewer and Redmond ${ }^{16}$ have argued that an "even more pertinent form of anxiety - 'sport injury trait anxiety' - may fare even better than competitive trait anxiety in predicting injury"; however, to date, no empirical evidence exists in support of such construct as it is yet to be formally conceptualized and measured. It must also be noted that, in general, empirical evidence for understanding psychosocial antecedents to anxiety in a sport injury occurrence is still in its infancy, and further prospective studies for greater clarification and understanding are required. However, based on the findings to date, it is known that anxiety as a co-antecedent to individual's response to a potentially stressful situation can amplify individual's risk of encountering a sport injury.

\section{Anxiety and sport injury rehabilitation}

Similar to competitive sport performance and sport injury occurrence contexts, existing theoretical conceptualizations ${ }^{31}$ and empirical evidence has also acknowledged the role of stress and anxiety as part of the sport injury rehabilitation process. In fact, anxiety has been found to influence both orthopedic/musculoskeletal and concussion injuries alike. ${ }^{43}$ Building on the pre-injury conceptualizations, ${ }^{23,32}$ the Integrated Model of Psychological Response to the Sport Injury and Rehabilitation Process ${ }^{31}$ presumes that following injury occurrence, the injury itself becomes a stressor that will be consequently cognitively appraised, resulting in bidirectional interaction between emotional and behavioral responses and any subsequent cognitive appraisals known as the dynamic 
core. ${ }^{31}$ Along with the preinjury factors as identified in the Andersen and Williams model, ${ }^{23,32}$ the dynamic core is also influenced by a number of additional personal and situational factors, which can influence overall psychosocial and physical injury recovery outcomes. For more details on the Integrated model, please see the original work by WieseBjornstal et al. ${ }^{31}$

The Integrated model ${ }^{31}$ proposes that anxiety, as a personality variable, can influence sport injury rehabilitation and successful recovery outcomes in a number of ways. First, it can carry over from being a pre-injury factor influencing injury occurrence, to a personal factor influencing an individual's cognitive appraisals of the injury and the rehabilitation process. ${ }^{31}$ Thus far, literature has suggested that immediately following an injury during the reaction to injury phase, ${ }^{44}$ an athlete is likely to experience anxiety related to both the injury and the recovery process. ${ }^{44,45}$ Once the athlete progresses to the rehabilitation phase, ${ }^{44}$ anxiety is typically more likely to be associated with their performance in new rehabilitation activities and/or using the injured body part. A number of studies with sport medicine professionals such as athletic trainers and physiotherapists worldwide have also indicated that the prevalence of stress and anxiety are among the most pertinent factors distinguishing athletes who cope well with their injuries from those who do not. ${ }^{46-50}$

The relationship between stress/anxiety and coping with injuries is also strongly related to the physical progress an athlete makes during the rehabilitation process. ${ }^{30}$ When physical progress is consistent with an athlete's own perceptions of rehabilitation success, it is likely that feelings of anxiety and other negative emotions/cognitive appraisals will decrease over time. ${ }^{51}$ However, when such progress does not occur as desired, or at times of setbacks, anxiety is likely to increase, and an anxious athlete is at greater risk for developing feelings of depression, particularly when they also have a high sense of athletic identity. ${ }^{52}$

\section{Anxiety and return to sport}

The final phase of rehabilitation is concerned with an athlete's safe physical and psychosocial return to sport. ${ }^{44}$ Often these two aspects are not valued equally, ${ }^{16}$ and emphasis is often placed on the physical ability and readiness to return to sport. However, given the cyclical nature of cognitive appraisals, and emotional and behavioral responses during the sport injury rehabilitation process, ${ }^{53,54}$ anxiety, as an emotional response, can significantly influence successful return to sport as well.
Thus far, research has identified fear and reinjury anxiety (often these terms are used interchangeably in the literature although they are not the same construct ${ }^{55,56}$ ) as the main concern for athletes during the return to sport process. ${ }^{52,53,57-61}$ Research suggests that reinjury anxiety can negatively impact athletic performance after returning from injury. ${ }^{41,57}$ An athlete may be hesitant to give $100 \%$ due to lack of confidence in the injured body part resulting in increased worry and tension. Podlog and Eklund ${ }^{57}$ have argued that reinjury anxiety during the return to sport phase can be detrimental for an athlete as it can lead to an increased risk of reinjury or secondary injury. In addition, anxieties related to the inability and/or uncertainty to return to pre-injury level of performance and lack of athletic appearance ${ }^{57,62}$ have been found to influence a successful return to sport process. Moreover, lack of athletic identity, feelings of isolation, and pressures to return to sport when the athletes themselves do not feel ready to return ${ }^{52,57}$ are also typical emotional responses during the return to sport phase, and they are likely to increase anxiety if not addressed.

\section{Addressing anxiety with athletes}

Given the significance of anxiety in sport performance, it is important to ensure it is addressed early and by appropriately trained mental health professionals. Anxiety, even though it is a normal emotion experienced by many, if left unaddressed, can lead to more serious psychological disorders. Recognizing early signs and symptoms of anxiety typically fall on those professionals interacting with athletes on a daily basis. Any medically unexplainable changes in resting heart rate, or muscle tension should be noted, and when coupled with increases in life and sport-related stressors, sudden changes in mood, and emergence of unusual behaviors could be signs of increased stress and/or anxiety.

To help detect athletes at risk, it would be advisable for appropriately trained clinicians to implement valid and reliable mental health screening tools into pre-participation medical examinations. Such baseline measures can help later to identify any possible significant changes, and assist in early intervention and referral when necessary. ${ }^{63}$ The baseline assessments can also be beneficial at the time of injury, which, if used by appropriately trained professionals, can also be beneficial in determining athletes' psychological readiness to return to sport. ${ }^{64}$ For more details on how to conduct mental health screening and assess clinical issues with athletes, please see recent comprehensive text edited by Jim Taylor. ${ }^{63}$

In addition to assessment, a number of psychosocial interventions can be beneficial to help athletes cope with stressful situations and anxiety, in general. Depending on the 
individual athlete's needs, these could be interventions that aim to provide athletes an ability to manage their unrealistic or irrational cognitive appraisals, debilitative emotional responses, nonbeneficial behaviors, and/or physiological symptoms. Some of the most commonly used psychosocial interventions include goal setting, imagery, relaxation strategies, self-talk, and social support. ${ }^{2,65,66}$ As the aim of any psychological intervention is to assist the athlete in the development of self-regulatory skills, ${ }^{67}$ and the intervention should be grounded in appropriate psychological theory and empirical evidence, ${ }^{2}$ they should be designed and implemented by professionals trained to do so. It would be advisable to ensure we, as healthcare professionals, work together in a holistic, interprofessional manner ${ }^{68-71}$ to ensure we deliver client-specific and practitioner competent care. ${ }^{65}$

\section{Conclusion}

The current article has discussed the role of anxiety in a range of sport-related performance situations. Since ample evidence exists for the role of sport-related anxiety in competitive settings, ${ }^{5,13-15}$ the current article shifted its' focus to how anxiety affects other sport-related performance domains, namely, sport injury occurrence, rehabilitation, and return to sport.

Considering the original theoretical conceptualization by Smith and Smoll, ${ }^{4}$ and the models of sport injury ${ }^{23,30-32}$ together with the empirical evidence to date, it can be argued that sport-related anxiety can have a significant negative impact on the athlete. All of the theoretical conceptualizations reviewed are grounded in the cognitive appraisal physiological arousal relationship known as the stress response to a potentially stressful situation and highlight the importance of understanding anxiety as a psychophysical phenomenon.

If left unaddressed, sport-related anxiety can continue to have spiraling effects on an athlete's performance. In short, sport-related anxiety can 1) have a negative impact on sport performance during practice and competitions, 2) lead to increased risk of injury occurrence, 3) delay and obstruct injury rehabilitation and the return to sport process, and 4) increase subsequent reinjury risk during post-rehabilitation practice and competitions.

Given the above, those working with athletes should be mindful of how anxiety can influence athletes' cognitive appraisals, physiological arousals, and ultimately, performance in a range of performance related situations. Moreover, they should be mindful of how anxiety can transfer itself from one situation to another, and how this may vary depending on the athlete in question. It is also important to remember our role as part of a holistic, interprofessional team. ${ }^{68-71}$ To appropriately recognize and treat sport-related anxiety, we as professionals must ensure that we provide each of the athletes we work with client-specific and practitioner competent care, ${ }^{65}$ and refer to other professionals when necessary. ${ }^{16}$

\section{Disclosure}

The authors report no conflicts of interest in this work.

\section{References}

1. Hanton S, Mellalieu S, Williams JM. Understanding and managing stress in sport. In: Williams JM, Krane V, editors. Applied Sport Psychology: Personal Growth to Peak Performance. 7th ed. New York, NY: McGrawHill; 2015:207-239.

2. Weinberg RS, Gould D. Foundations of Sport and Exercise Psychology. 6th ed. Champaign, IL: Human Kinetics; 2015.

3. Cheng WKN, Hardy L, Markland D. Toward a three-dimensional conceptualization of performance anxiety: rationale and initial measurement development. Psychol Sport Exercise. 2009;10(2):271-278.

4. Smith RE, Smoll FL. Sport performance anxiety. In: Leitenberg H, editor. Handbook of Social and Evaluation Anxiety. New York, NY: Plenum Press; 1990:417-454.

5. Patel DR, Omar H, Terry M. Sport-related performance anxiety in young female athletes. J Pediatr Adolesc Gynecol. 2010;23(6):325-335.

6. Yerkes RMD, Dodson JD. The relation of strength of stimulus to rapidity of habit formation. J Comp Neurol Psychol. 1908;18(5):459-482.

7. Hull CL. Principles of behavior: An Introduction to Behavior Theory. New York, NY: Appleton-Century-Crofts; 1943.

8. Apter MJ. The Experience of Motivation: The Theory of Psychological Reversals. London: Academic Press; 1982.

9. Martens R, Vealey RS, Burton D. Competitive Anxiety in Sport. Champaign, IL: Human Kinetics; 1990.

10. Hardy L, Parfitt G. A catastrophe model of anxiety and performance. Br J Psychol. 1991;82:163-178.

11. Hanin YL. Emotions and athletic performance: Individual Zones of Optimal Functioning model. Eur Yearbook Sport Psychol. 1997;1:29-72.

12. Woodman TH, L. Stress and anxiety. In: Singer RH, H A, Janelle CM, editors. Handbook of Research on Sport Psychology. New York, NY: Wiley; 2001:290-318.

13. Craft L, Magyar T, Becker BJ, Feltz DL. The relationship between the Competitive State Anxiety Inventory-2 and sport performance: a metaanalysis. J Sport Exerc Psychol. 2003;25:44-65.

14. Woodman T, Hardy L. The relative impact of cognitive anxiety and self-confidence upon sport performance: a meta-analysis. J Sports Sci. 2003;21(6):443-457.

15. Jokela M, Hanin YL. Does the individual zones of optimal functioning model discriminate between successful and less successful athletes? A meta-analysis. J Sports Sci. 1999;17(11):873-887.

16. Brewer BW, Redmond C. Psychology of Sport Injury. Champaign, IL: Human Kinetics; 2016.

17. Duncan MJ, Chan CKY, Clarke ND, Cox M, Smith M. The effect of badminton-specific exercise on badminton short-serve performance in competition and practice climates. Eur J Sport Sci. 2017;17(2):119.

18. Duncan MJ, Smith M, Bryant E, et al. Effects of increasing and decreasing physiological arousal on anticipation timing performance during competition and practice. Eur J Sport Sci. 2016;16(1):27-35.

19. Balyan KY, Tok S, Tatar A, Binboga E, Balyan M. The relationship among personality, cognitive anxiety, somatic Anxiety, physiological arousal, and performance in male athletes. J Clin Sport Psychol. 2016;10:48-58. 
20. Geukes K, Harvey JT, Trezise A, Mesagno C. Personality and performance in real-world competitions: testing trait activation of fear of negative evaluation, dispositional reinvestment, and athletic identity in the field. Psychol Sport Exercise. 2017;30:101-110.

21. Noteboom JT, Barnholt KR, Enoka RM. Activation of the arousal response and impairment of performance increase with anxiety and stressor intensity. J Appl Physiol (1985). 2001;91(5):2093-2101.

22. Hammermeister J, Burton D. Stress, appraisal, and coping revisited: Examining the antecedents of competitive state anxiety with competitive endurance athletes. Sport Psychol. 2001;15:66-90.

23. Williams J, Andersen M. Psychosocial antecedents of sport injury: review and critique of the stress and injury model. J Sport Exercise Psychol. 1998;10:5-25.

24. Andersen MB, Williams JM. Athletic injury, psychosocial factors, and perceptual changes during stress. J Sports Sci. 1999;17(9):735-741.

25. Dvorak J, Junge A, Chomiak J, et al. Risk factor analysis for injuries in football players: possibilities for a prevention program. Am J Sports Med. 2000;28(90005):69S-74S.

26. Rogers TJ, Landers DM. Mediating effects of peripheral vision in the life event stress/athletic injury relationship. J Sport Exercise Psychol. 2005;27(3):271-288.

27. Ford IW, Eklund RC, Gordon S. An examination of psychosocial variables moderating the relationship between life stress and injury time-loss among athletes of a high standard. J Sports Sci. 2000;18:301-213.

28. Kolt GS, Kirkby RJ. Injury, anxiety, and mood in competitive gymnasts. Percept Mot Skills. 1994;78(3):955-962.

29. Lavallee D, Flint F. The relationship of stress, competitive anxiety, mood state, and social support to athletic injury. J Athl Train. 1996;31(4):296-299.

30. Brewer BW, Andersen MB, Van Raalte JL. Psychological aspects of sport injury rehabilitation: toward a biopsychological approach. In: Mostofsky DI, Zaichkowsky LD, editors. Medical Aspects of Sport and Exercise. Morgantown, WV: Fitness Information Technology; 2002:41-54.

31. Wiese-Bjornstal DM, Smith AM, Shaffer SM, Morrey MA. An integrated model of response to sport injury: psychological and sociological dynamics. J Appl Sport Psychol. 1998;10(1):46-69.

32. Andersen M, Williams J. A model of stress and athletic injury: prediction and prevention. J Sport Exercise Psychol. 1988;10:294-306.

33. Appaneal RN, Habif S. Psychological antecedents to sport injury. In: Arvinen-Barrow M, Walker N, editors. Psychology of Sport Injury and Rehabilitation. Abingdon: Routledge; 2013:6-22.

34. Williams JM, Andersen MB. Psychosocial antecedents of sport injury and interventions for risk reduction. In: Tenenbaum G, Eklund R, editors. Handbook of Sport Psychology. 3rd ed. Hoboken, NJ: Wiley; 2007:379-403.

35. Cagle A, Overcash K, Rowe D, Needle A. Trait anxiety as a risk factor for musculoskeletal injury in athletes: a critically appraised topic. Int J Athl Train Ther. 2017;22(3):26-31.

36. Kontos A. Perceived risk, risk taking, estimation of ability and injury among adolescent sport participants. J Pediatr Psychol. 2004;29(2):447-455.

37. Gnacinski SL, Arvinen-Barrow M, Brewer BW, Meyer BB. Factorial validity and measurement invariance of the perceived susceptibility to sport injury scale. Scand J Med Sci Sports. 2017;27(7):754-761.

38. Reuter JM, Short SE. The relationships among three components of perceived risk of injury, previous injuries and gender in non-contact/ limited contact sport athletes. Athl Insight Online J Sport Psychol. 2005;7(1):20-42.

39. Deroche TS, Y, Brewer B, Le ScanffC. Predictors of perceived susceptibility to sport-related injury. Pers Individ Differences. 2007;43:2218-2228.

40. Deroche T, Stephan Y, Woodman T, Le Scanff C. Psychological mediators of the sport injury-perceived risk relationship. Risk Anal. 2012;31(1):113-121.

41. Stephan Y, Deroche T, Brewer B, Caudroit J, Le Scanff C. Predictors of perceived susceptibility to sport-related injury among competitive runners: the role of previous experience, neuroticism, and passion for running. Appl Psychol. 2009;58(4):672-687.
42. Binboga E, Guven S, Çatıkkaş F, Bayazıt O, Tok S. Psychophysiological responses to competition and the Big Five personality traits. J Hum Kinet. 2012;33:187-194.

43. Covassin T, Crutcher B, Bleecker A, Heiden EO, Dailey A, Yang J. Postinjury anxiety and social support among collegiate athletes: a comparison between orthopedic injuries and concussions. J Athl Training. 2014;49(4):462-468.

44. Kamphoff C, Thomae J, Hamson-Utley JJ. Integrating the psychological and physiological aspects of sport injury rehabilitation: rehabilitation profiling and phases of rehabilitation. In: Arvinen-Barrow M, Walker N, editors. Psychology of Sport Injury and Rehabilitation. Abingdon: Routledge; 2013:134-155.

45. Hamson-Utley JJ. Psychology of sport injury: a holistic approach to rehabilitating the injured athlete. Chin J Sports Med. 2010;29(3):343-347.

46. Arvinen-Barrow M, Hemmings B, Weigand DA, Becker CA, Booth L. Views of chartered physiotherapists on the psychological content of their practice: a national follow-up survey in the United Kingdom. $J$ Sport Rehabil. 2007;16(2):111-121.

47. Clement D, Granquist M, Arvinen-Barrow M. Psychosocial aspects of athletic injuries as perceived by athletic trainers. J Athl Train. 2013;48(4):512-521.

48. Heaney C. Physiotherapists' perceptions of sport psychology intervention in professional soccer. Int J Sport Exerc Psychol. 2006(4):67-80.

49. Francis SR, Andersen MB, Maley P. Physiotherapists' and male professional athletes' views on psychological skills for rehabilitation. $J \mathrm{Sci}$ Med Sport. 2000;3(1):17-29.

50. Hemmings B, Povey L. Views of chartered physiotherapists on the psychological content of their practice: a preliminary study in the United Kingdom. Br J Sports Med. 2002;36(1):61-64.

51. Houston MN, Cross KM, Saliba SA, Hertel J. Injury-related fear in acutely injured interscholastic and intercollegiate athletes. Athl Trai Sports Health Care. 2014;13:288-294.

52. Podlog L, Wadey R, Stark A, Lochbaum M, Hannon J, Newton M. An adolescent perspective on injury recovery and the return to sport. Psychol Sport Exerc. 2013;14(4):437-446.

53. Ruddock-Hudson M, O'Halloran P, Murphy G. The psychological impact of long-term injury on Australian football league players. $J \mathrm{Appl}$ Sport Psychol. 2014;26(4):377-394.

54. Clement D, Arvinen-Barrow M, Fetty T. Psychosocial responses during different phases of sport-injury rehabilitation: a qualitative study. $J$ Athl Train. 2015;50(1):95-104.

55. Walker N, Thatcher J. The emotional response to athletic injury: Re-injury anxiety. In: Thatcher J, Jones MV, Lavallee D, editors. Coping and Emotion in Sport. 2nd ed. New York, NY: Routledge; 2011: 235-259.

56. Walker N. The Meaning of Sports Injury and Re-injury Anxiety Assessment and Intervention. Aberystwyth: University of Wales; 2006.

57. Podlog L, Dimmock J, Miller J. A review of return to sport concerns following injury rehabilitation: practitioner strategies for enhancing recovery outcomes. Phys Ther Sport. 2011;12(1):36-42.

58. Podlog L, Eklund RC. Professional coaches' perspectives on the return to sport following serious injury. JAppl Sport Psychol. 2007;19(2):207-225.

59. Podlog L, Hannon JC, Banham SM, Wadey R. Psychological readiness to return to competitive sport following injury: a qualitative study. Sport Psychol. 2015;29(1):1-14.

60. Podlog L, Lochbaum M, Stevens T. Need satisfaction, well-being, and perceived return to sport outcomes among injured athletes. J Appl Sport Psychol. 2010;22(2):167-182.

61. Wierike SM, Sluis A, van der Sluis A, van den Akker-Scheek I, ElferinkGemser MT, Visscher C. Psychosocial factors influencing the recovery of athletes with anterior cruciate ligament injury: a systematic review. Scand J Med Sci Sports. 2013;23(5):527-540.

62. Podlog L, Eklund RC. A longitudinal investigation of competitive athletes' return to sport following serious injury. J Appl Sport Psychol. 2006;18(1):44-68.

63. Taylor J, editor. Assessment in Applied Sport Psychology. Champaign, IL: Human Kinetics; 2017. 
64. Arvinen-Barrow M, Hamson-Utley JJ, DeFreese JD. Sport injury, rehabilitation, and return to sport. In: Taylor J, editor. Assessment in Sport Psychology Consulting. Champaign, IL: Human Kinetics; 2017.

65. Ray R, Wiese-Bjornstal DM, editors. Counseling in Sports Medicine. Champaign, IL: Human Kinetics; 1999.

66. Arvinen-Barrow M, Walker N, editors. Psychology of Sport Injury and Rehabilitation. Abington: Routledge; 2013.

67. Crews DJ. Self-regulation strategies in sport and exercise. In: Singer RN, Murphy M, Tennant LK, editors. Handbook of Research on Sport Psychology. New York, NY: Macmillan; 1993:557-568.

68. Clement D, Arvinen-Barrow M. Sport medicine team influences in psychological rehabilitation: a multidisciplinary approach. In: ArvinenBarrow M, Walker N, editors. The Psychology of Sport Injury and Rehabilitation. Abingdon: Routledge; 2013:156-170.
69. Meyer BB, Merkur A, Ebersole KT, Massey WV. The realities of working in elite sport. What they didn't teach you in graduate school. In: Lane AM, Godfrey RJ, Loosemore M, Whyte GP, editors. Applied Sport Science and Medicine: Case Studies from Practice. CreateSpace: Self-published; 2014:137-142.

70. Arvinen-Barrow M, Clement D. A preliminary investigation into athletic trainers' views and experiences of multidisciplinary team approach to sport injury rehabilitation. Athl Train Sports Health Care. 2015;7(3):97-107.

71. Arvinen-Barrow M, Clement D. Preliminary investigation into sport and exercise psychology consultants' views and experiences of an interprofessional care team approach to sport injury rehabilitation. J Interprof Care. 2017;31(1):66-74.
Open Access Journal of Sports Medicine

\section{Publish your work in this journal}

The Open Access Journal of Sports Medicine is an international, peer-reviewed, open access journal publishing original research, reports, reviews and commentaries on all areas of sports medicine. The journal is included on PubMed. The manuscript management system is completely online and includes a very quick and fair
Dovepress

peer-review system. Visit http://www.dovepress.com/testimonials.php to read real quotes from published authors. 